\title{
SUICIDE ATTEMPTS AND RELATED RISK FACTORS IN PATIENTS ADMITTED TO TERTIARY CARE CENTRE IN SOUTH INDIA
}

\author{
Sumanth Tarikere Parameshwaraiah'1, Shivananda Manohar², Kuppuswami Thiagarajan ${ }^{3}$ \\ ${ }_{1}^{1}$ Assistant Professor, Department of Psychiatry, Rajarajeshwari Medical College and Hospital, Bangalore, Karnataka, India. \\ 2Senior Resident, Department of Psychiatry, JSS Medical College and Hospital, JSS Academy for Higher Education, Mysore, Karnataka, \\ India. \\ ${ }^{3}$ Consultant Psychiatrist, Thanjavur, Tamilnadu, India.
}

ABSTRACT

\section{BACKGROUND}

In India, the number of suicides and attempted suicides have increased significantly. Moreover, the suicide attempt rates are found to be higher than rates for completed suicides. Therefore, present study aimed to investigate the socio-demographic characteristics and suicide data on attempted suicides.

\section{MATERIALS AND METHODS}

75 cases of attempted suicide individuals admitted to MVJ Medical College and Research Hospital, when declared medically/surgically stable and referred to Psychiatry Department, were recruited for the study. Detailed interview with the patient was conducted and information obtained was compiled in a specially designed proforma.

\section{RESULTS}

Majority of the subjects were aged less than 30 years (77.3\%), females (66.7\%), married (56\%), educated only up to high school or less (70.7\%), were Hindus (90.7\%) and from nuclear family (73.3\%). Housewives (30.7\%) and farmers (21.35\%) were the common occupational groups. Significant past and family history of suicidal behaviour, psychiatric and physical illness was present. Most attempts took place at patient's house (78.7\%). Organophosphorus compound poisoning was the most common method of attempt (38.7\%) with interpersonal problems in the family (38.7\%) as the most common precipitating factor.

\section{CONCLUSION}

In conclusion young adults, females with low socio-economic and educational status, having significant past and family history of suicidal behaviour and psychiatric illnesses were at increased risk of suicide attempt. High intent among suicide attempters was associated with high hopelessness score and presence of current psychiatric illness. Also, high hopelessness score was associated with presence of current psychiatric illness.

\section{KEY WORDS}

Suicide Attempt, Suicide Risk Factors, Hopelessness.

HOW TO CITE THIS ARTICLE: Parameshwaraiah ST, Manohar S, Thiagarajan K. Suicide attempts and related risk factors in patients admitted to tertiary care centre in South India. J. Evolution Med. Dent. Sci. 2018;7(25):2916-2920, DOI: $10.14260 /$ jemds/2018/657

\section{BACKGROUND}

Suicide and suicide attempts are serious public health problem in developed countries.1,2 Suicide is the most common among several mental health problems, which leads to death in all age groups in majority of countries. ${ }^{3}$ Furthermore, the attempted suicides are 10 - 40 times more frequent than completed suicide. In 2002, the world health organisation found 877,000 deaths were due to suicide (Geneva). The recent Indian epidemiologic studies found more than one lakh persons lost their lives by committing suicide during the year 2008. Furthermore, the studies in Sikkim reported the highest rate of suicide (48.2) followed by Pondicherry (46.9) and suicide rate in Andhra Pradesh was 17.4 in 2008 (National Crime Records Bureau, 2008).4

\section{'Financial or Other Competing Interest': None.}

Submission 24-05-2018, Peer Review 05-06-2018,

Acceptance 08-06-2018, Published 18-06-2018.

Corresponding Author:

Dr. Shivananda Manohar,

Senior Resident, Department of Psychiatry,

JSS Medical College and Hospital,

JSS Academy for Higher Education,

Mysore, Karnataka, India.

E-mail:drshivman@gmail.com

DOI: $10.14260 /$ jemds $/ 2018 / 657$

\section{(c) $(1) \ominus$}

Therefore, the prevention of suicide and suicide attempts has become central to mental health policy in many countries. ${ }^{5}$

In studies conducted worldwide as well as in India, several risk factors which were observed to be associated with an increased risk of suicide and attempted suicide 6 included psychiatric disorders, 7,8 feelings of hopelessness and impulsivity, ${ }^{9}$ history of previous suicide attempts, ${ }^{7}$ age, ${ }^{10}$ gender ${ }^{11}$ and race, ${ }^{12}$ marital status, occupation, education, religion, place of residence ${ }^{10,11,13}$ and adverse childhood experiences ${ }^{14}$ and family history. ${ }^{15}$ Previous epidemiologic studies have focused on completed suicide rather than attempted suicide, 16 since data resulting from the former are systematically gathered. A very little attention has been paid to persons who are hospitalised after attempted suicide, despite accumulating evidence that their rate of subsequent suicide is much higher than expected $(8$ - 10). However, hospitalisation after attempted suicide offers a chance for treatment intervention in a group well known to be at high risk for later suicide.

Therefore, present study aimed to find the risk factors with reference to socio-demographic characteristics, family background, physical and psychiatric morbidity in cases of attempted suicide individuals admitted to tertiary care centre in Bangalore, South India. 


\section{MATERIALS AND METHODS}

This cross-sectional study population included all patients, who were hospitalised with a diagnosis of attempted suicide (International Classification of Diseases, Tenth Revision (ICD10), codes X60-X84, code Z72.8 or code Z91.5) from January 2009 to December 2011. This study was conducted at MVJ Medical College and Research Hospital, Bangalore, Karnataka, India. This is a large teaching hospital and tertiary referral centre in South Indian region. 75 (33.3\% males and 66.7\% females) patients were included upon inclusion criteria such as age 15 and above and below 65 years and patients available with reliable informant. The patients with unstable medical conditions, mental retardation and those who refuse to give consent were excluded from this study. The study was approved by the Institutional Ethics Committee of the MVJ Medical College and Research Hospital, Bangalore, India. A written informed consent was obtained from the study participants. Socio-demographic data and suicide attempt data were taken from the patients. MINI Plus 5.0.0 (Mini International Neuropsychiatric Interview) was administered to assess psychiatric illness and the diagnosis was confirmed in accordance to ICD 10. A supportive psychotherapeutic relationship was maintained with all the subjects till they were discharged. Furthermore, a semi-structured questionnaire was designed in the Department of Psychiatry keeping in view all the requirements, which are necessary for this study. The socio-demographic details included are age, gender, marital status, education, occupation, place of residence, employment status religion and socio-economic status. The suicide attempt data included nature of attempt, prior thoughts of attempt, history of previous suicidal attempts, reasons for attempt, mode of attempt and family history of suicide.

\section{Statistical Analysis}

The quantitative variables are expressed as mean \pm standard deviation (SD). The qualitative variables are expressed as an absolute value (n) and the percentage with the estimation of the 95\% Confidence Interval (CI). Qualitative variables associations were analysed using the Pearson Chi-square test. All statistical analyses were performed using SPSS 16.0 (SPSS, Inc., Chicago, USA). P values $<0.05$ were considered to be statistically significant.

\section{RESULTS}

Socio-Demographic Characteristics and Suicide Attempt Data

The present study included 75 (mean age $25.5 \pm 6.87$ years) suicide attempted individuals who were admitted in the MVJ Medical College and Research Hospital, Bangalore. The sociodemographic characteristics of studied individuals were documented in Table 1 . Among them, $33 \%$ were male $(25.3 \pm$ 6.31 years $)$ and $67 \%$ were $(25.5 \pm 7.1)$ female subjects. Most of the suicide attempters were in $15-24$ years age individuals. Predominantly, married (56\%), nuclear family set-up (73\%), educated upto high school (36\%), housewives (31\%) and their religion was Hindu (91\%) (Table 1). The suicide attempt data was documented in Table 2 . The most frequent method adopted for attempting suicide was the consumption of organophosphorus compound (38\%) followed by chemical poisons (27\%). Family problems (38\%) were found to be the most common reason for the suicidal attempt followed by marital relationship issues (33\%), problem related to love affairs (8\%) and financial problems (5\%). Among them the alcohol dependence was $16 \%$. Only $28 \%$ presented with a history of previous suicidal attempt and family history of suicidal attempt was found to be $13 \%$ in our region.

\section{Suicide Attempters on Beck's Hopelessness Scale}

The Beck Hopelessness Scale (BHS) is a 20-item self-report measure designed to assess an individual's level of hopelessness. In present study the socio-demographic characteristics (Table 3) and suicide attempt data (Table 4) on Beck's Hopelessness Scale was documented. In our study none of the possible confounding factors such as gender, socio-economic status $(\mathrm{p}=0.569)$, marital status $(\mathrm{p}=0.168)$, education $(p=0.260)$ and occupation $(p=0.346)$ had $a$ significant effect, nor were there significant interactions (Table 3). Similarly, the data on suicide attempt such as past history of physical illness ( $p=0.830$ ), family history of suicide $(p=0.489)$, family history of psychiatric illness $(0.141)$ and method of suicide attempt (0.091) was also not found to be of significant effect and interactions on Beck's Hopelessness Scale (Table 4).

\begin{tabular}{|c|c|c|}
\hline \multirow{2}{*}{ Age } & Variables & Number of Subjects (\%) \\
\cline { 2 - 3 } & $15-24$ & $41(54)$ \\
\cline { 2 - 3 } & $25-44$ & $30(40)$ \\
\hline \multirow{3}{*}{ Gender } & $>45$ & $25(6)$ \\
& Male & $50(66)$ \\
\cline { 2 - 3 } & Female & $55(73)$ \\
\hline \multirow{3}{*}{ Family set-up } & Nuclear & $8(11)$ \\
\cline { 2 - 3 } & Joint & $12(16)$ \\
\cline { 2 - 3 } & Extended & $42(56)$ \\
\hline \multirow{3}{*}{ Marital status } & Married & $29(39)$ \\
\cline { 2 - 3 } & Unmarried & $3(4)$ \\
\cline { 2 - 3 } & Separated & $1(1)$ \\
\cline { 2 - 3 } & Widow & $15(19)$ \\
\hline \multirow{3}{*}{ Education } & PUC & $27(36)$ \\
\cline { 2 - 3 } & High School & $19(26)$ \\
\cline { 2 - 3 } & Higher Secondary & $8(11)$ \\
\cline { 2 - 3 } \\
\cline { 2 - 3 } & Graduate & $6(8)$ \\
\hline
\end{tabular}




\begin{tabular}{|c|c|c|}
\hline & Christian & $6(8)$ \\
\hline & Muslim & $1(1)$ \\
\hline \multirow{5}{*}{ Occupation } & Unemployed & $10(13)$ \\
\hline & Employed & $18(24)$ \\
\hline & Students & $8(11)$ \\
\hline & Housewives & $23(31)$ \\
\hline & Farmers & $16(21)$ \\
\hline & phic Charact & \\
\hline
\end{tabular}

\begin{tabular}{|c|c|c|}
\hline \multirow{4}{*}{ Method of suicide attempt } & Variables & Number of Subjects (\%) \\
\cline { 2 - 3 } & Organophosphorus compound & $28(38)$ \\
\cline { 2 - 3 } & Drug overdosage & $15(20)$ \\
\cline { 2 - 3 } & Other chemical poisons & $20(27)$ \\
\cline { 2 - 3 } & Hanging & $8(5)$ \\
\hline \multirow{4}{*}{ Reasons for suicide attempt } & Other methods & $29(38)$ \\
\cline { 2 - 3 } & Family problems & $25(33)$ \\
\cline { 2 - 3 } & Marital discord & $6(8)$ \\
\cline { 2 - 3 } & Problem related to love affair & $4(5)$ \\
\cline { 2 - 3 } & Financial problem & $11(14)$ \\
\hline \multirow{3}{*}{ Place of suicide attempt } & Others & $59(79)$ \\
\cline { 2 - 3 } & Home & $7(9)$ \\
\cline { 2 - 3 } & Farm & $9(12)$ \\
\hline \multirow{2}{*}{ History of previous attempt } & Other place & $21(28)$ \\
\cline { 2 - 3 } & Yes & $54(72)$ \\
\hline \multirow{2}{*}{ Family History of suicide attempt } & No & $10(13)$ \\
\hline \multirow{2}{*}{ Alcohol use among attempters } & Yes & $65(86)$ \\
\cline { 2 - 3 } & No & $12(16)$ \\
\cline { 2 - 3 } & Yes & $63(84)$ \\
\hline
\end{tabular}

\begin{tabular}{|c|c|c|c|c|c|c|}
\hline \multirow{2}{*}{\multicolumn{2}{|c|}{ Variable }} & \multicolumn{4}{|c|}{ Beck's Hopelessness Rating } & \multirow[t]{2}{*}{ P-value } \\
\hline & & \multirow{2}{*}{$\begin{array}{c}\text { Minimal (\%) } \\
7(28.0)\end{array}$} & \multirow{2}{*}{$\begin{array}{c}\text { Mild (\%) } \\
7(28.0)\end{array}$} & \multirow{2}{*}{$\begin{array}{c}\text { Moderate (\%) } \\
5(20.0)\end{array}$} & \multirow{2}{*}{$\begin{array}{c}\text { Severe (\%) } \\
6(24.0)\end{array}$} & \\
\hline \multirow{2}{*}{ Sex } & Male & & & & & \multirow{2}{*}{0.746} \\
\hline & Female & $14(28.0)$ & $9(18.0)$ & $14(28.0)$ & $13(26.0)$ & \\
\hline \multirow{4}{*}{$\begin{array}{l}\text { Marital } \\
\text { status }\end{array}$} & Single & $10(34.5)$ & $8(27.6)$ & $3(10.3)$ & $8(7.6)$ & \multirow{4}{*}{0.168} \\
\hline & Married & $11(26.2)$ & $7(16.7)$ & $15(35.7)$ & $9(21.4)$ & \\
\hline & Separated & $\begin{array}{ll}0 & (0) \\
\end{array}$ & $1(33.3)$ & $0(0)$ & $2(66.7)$ & \\
\hline & Widow & $0(0)$ & $0(0)$ & $1(100.0)$ & $0(0)$ & \\
\hline \multirow{2}{*}{ Socio-economic status } & Low & $20(29.4)$ & $14(20.6)$ & $16(23.5)$ & $18(26.5)$ & \multirow{2}{*}{0.569} \\
\hline & Middle & $1(14.3)$ & $2(28.6)$ & $3(42.9)$ & $1(14.3)$ & \\
\hline \multirow{3}{*}{ Religion } & Hindu & 29.4 & 19.1 & 27.9 & 23.5 & \multirow{3}{*}{0.253} \\
\hline & Muslim & 16.7 & 33.3 & 0.0 & 50.0 & \\
\hline & Christian & 0 & 100.0 & 0 & 0 & \\
\hline \multirow{6}{*}{ Education } & Illiterate & $1(16.7)$ & $3(50.0)$ & $2(33.3)$ & $0(0)$ & \multirow{6}{*}{0.260} \\
\hline & Lower primary & $2(28.6)$ & $3(42.9)$ & $1(14.3)$ & $1(14.3)$ & \\
\hline & Higher primary & $2(15.4)$ & $2(15.4)$ & $4(30.8)$ & $5(38.5)$ & \\
\hline & High school & $10(37.0)$ & $2(7.4)$ & $6(22.2)$ & $9(33.3)$ & \\
\hline & PUC & $4(28.6)$ & $4(14.3)$ & $4(28.6)$ & $4(28.6)$ & \\
\hline & Graduate & $2(25.0)$ & $3(50.0)$ & $2(25.0)$ & $0(0)$ & \\
\hline \multirow{5}{*}{ Occupation } & Housewives & $6(26.1)$ & $3(13.0)$ & $7(30.4)$ & $7(30.4)$ & \multirow{5}{*}{0.346} \\
\hline & Farmers & $2(18.8)$ & $7(43.8)$ & $5(31.3)$ & $1(6.3)$ & \\
\hline & Students & $4(50.0)$ & $2(25.0)$ & $1(12.5)$ & $1(12.5)$ & \\
\hline & Skilled workers & $4(30.0)$ & $2(10.0)$ & $3(20.0)$ & $9(40.0)$ & \\
\hline & Unemployed & $4(40.0)$ & $2(20.0)$ & $3(30.0)$ & $\begin{array}{c}1 \\
(10.0)\end{array}$ & \\
\hline
\end{tabular}

\begin{tabular}{|c|c|c|c|c|c|c|}
\hline \multirow{2}{*}{\multicolumn{2}{|c|}{ Variable }} & \multicolumn{4}{|c|}{ Beck's Hopelessness Rating } & \multirow[t]{2}{*}{ P-value } \\
\hline & & \multirow{2}{*}{\begin{tabular}{|c|} 
Minimal (\%) \\
$19(28.4)$ \\
\end{tabular}} & \multirow{2}{*}{$\begin{array}{l}\text { Mild (\%) } \\
15(22.4)\end{array}$} & \multirow{2}{*}{\begin{tabular}{|c|} 
Moderate (\%) \\
$16(23.9)$
\end{tabular}} & \multirow{2}{*}{$\begin{array}{c}\text { Severe (\%) } \\
17(25.4)\end{array}$} & \\
\hline Pact $\mathrm{h} / \mathrm{n}$ nbycicalillnecs & Absent & & & & & \multirow{2}{*}{0.830} \\
\hline Past n/o pnysical ilmess & Present & $2(25.0)$ & $1(12.5)$ & $3(37.5)$ & $2(25.0)$ & \\
\hline \multirow{2}{*}{ Family h/o suicide } & Absent & $20(30.8)$ & $14(21.5)$ & $16(24.6)$ & $15(23.1)$ & \multirow{2}{*}{0.489} \\
\hline & Present & $1(10.0)$ & $2(20.0)$ & $3(30.0)$ & $4(40.0)$ & \\
\hline Family h/o psychiatric illness & Absent & $18(34.0)$ & $12(22.6)$ & $13(24.5)$ & $10(18.9)$ & 0.141 \\
\hline
\end{tabular}




\begin{tabular}{|c|c|c|c|c|c|c|}
\hline & Present & $3(13.6)$ & $4(18.2)$ & $6(27.3)$ & $9(40.9)$ & \multirow{3}{*}{0.223} \\
\hline \multirow{2}{*}{ Family h/o physical illness } & Absent & $19(31.1)$ & $11(18.0)$ & $17(27.9)$ & $14(23.0)$ & \\
\hline & Present & $2(14.3)$ & $5(35.7)$ & $2(14.3)$ & $5(35.7)$ & \\
\hline \multirow{2}{*}{ Substance use } & Absent & $19(30.2)$ & $12(19.0)$ & $15(23.8)$ & $17(27.0)$ & \multirow{2}{*}{0.493} \\
\hline & \begin{tabular}{|c|} 
Present \\
\end{tabular} & $2(16.7)$ & $4(33.3)$ & $4(33.3)$ & $2(16.7)$ & \\
\hline \multirow{6}{*}{ Method of suicide attempt } & Organophosphorus compound & $8(27.6)$ & $6(20.7)$ & $7(24.1)$ & $8(27.6)$ & \multirow{6}{*}{0.091} \\
\hline & Poisoning by other substances & $1(20.0)$ & $3(60.0)$ & $0(0)$ & $1(20.0)$ & \\
\hline & \begin{tabular}{|l|} 
Poisoning by chemical \\
\end{tabular} & $6(30.0)$ & $4(20.0)$ & $9(45.0)$ & $1(5.0)$ & \\
\hline & Drug overdosage & $6(40.0)$ & $3(20.0)$ & $1(6.7)$ & $5(33.3)$ & \\
\hline & Hanging & $0(0)$ & $0(0)$ & $1(25.0)$ & $3(75.0)$ & \\
\hline & Other methods & $0(0)$ & $0(0)$ & $1(50.0)$ & $1(50.0)$ & \\
\hline
\end{tabular}

\section{DISCUSSION}

In the present study we obtained the data on sociodemographic and suicide attempt profile of study subjects, among them oral consumption of organophosphorus compound and marital status was found to be an important factor for suicide attempt. Furthermore, Beck's Hopelessness Scale was found to be higher scale; however, there was no significant association observed in our population. In our study, majority of the suicide attempters were below 25 years of age (54\%). The data obtained in our sample was consistent with few earlier studies conducted in Pondicherry population, ${ }^{16}$ Chennai population, ${ }^{17}$ Kerala population ${ }^{13}$ and Ludhiana population. 18 These findings emphasise the need to target this age group for suicide risk assessment and management. Studies conducted in western populations have revealed that the female's suicide attempters are more predominant than the male subjects. ${ }^{19}$ Similar findings were observed in our study populations. In contradictory to this, majority of Indian studies showed the male preponderance. ${ }^{20}$ The high rate among females might be explained on the basis of psychological and socio-cultural reasons such as inadequate opportunities to express emotional conflicts and low social status of a woman in a family.

Most of our studied population was educated only up to high school or less $70.7 \%$. Similar results were observed in other studies conducted in different populations.13,21 However, the other study conducted by Indian population was observed that the majority of attempters were educated beyond matriculation (75\%). ${ }^{10}$ Majority of subjects were employed and only $16 \%$ of the sample was unemployed and this finding is similar to most of other Indian studies ${ }^{10,22}$ and differing from many western studies. ${ }^{23}$ Among females about $62 \%$ of them were either housewives or unemployed, who did not have a regular job with income. So, very low rate of suicide attempts was noted among professionals. Overall most people in our sample were married (56\%) compared to people who were single, separated or widowed. These findings were in agreement with most of Indian studies. ${ }^{10,11,20}$ However, study from Denmark reported cohabiting or single marital status was a significant risk factor for suicide. 15 Being separated or divorced was noted to be significantly associated with a suicidal act in another study. ${ }^{24}$

Positive family history of psychiatric illnesses, suicide and attempted suicide was found in significant number of attempters in our study. This was in agreement with most other studies, which studied this relationship in India and abroad.25,26 In our study a high rate of $58.7 \%$ with axis I disorder during the attempt was noted, even higher rates had been shown in many western studies and a few Indian studies. ${ }^{27}$ While some Indian studies showed rates similar to ours, ${ }^{10,16}$ there were others which had very low rate of psychiatric illnesses in suicide attempters. ${ }^{11,17}$ Possible reason for this variation could be due to differing geographic, cultural and economic background and also because of the fact that these studies were conducted across different timeline using different diagnostic/ classificatory systems.

In our study, significantly high suicide intent was seen in attempters with a high hopelessness score. There was statistically significant increase in the hopelessness score of attempters with a current psychiatric axis 1 diagnosis compared to those without any current psychiatric axis 1 diagnosis. Thus, our study showed that there was significant association between suicide intent, hopelessness and psychiatric diagnosis. Hopelessness is one of the core features in a depressed person. As depression and other mood disorders were the common psychiatric comorbidity in our patients, it is no surprise that there was high hopelessness score among these individuals compared to those patients with no significant psychiatric comorbidity. Attempters with a psychiatric diagnosis and high degree of hopelessness are more likely to have undergone more number of stressful life events in the preceding months or year. These patients had wrongly concluded that there was no possible solution to their problems and decided suicide to be the only way out from their untenable situation. Hence, it is likely that these persons aspired to have their act to end in a complete suicide. This high intentionality is expressed in their cognition, planning and the method chosen.

\section{CONCLUSION}

In conclusion, young adults, females with low socio-economic and educational status, having significant past and family history of suicidal behaviour and psychiatric illnesses were at increased risk of suicide attempt. High intent among suicide attempters was associated with high hopelessness score and presence of current psychiatric illness. Also, high hopelessness score was associated with presence of current psychiatric illness. However, further studies are warranted with large number of sample size to confirm our results.

\section{REFERENCES}

[1] Nock MK, Borges G, Bromet EJ, et al. Suicide and suicidal behavior. Epidemiol Rev 2008;30:133-54.

[2] Hawton K, van Heeringen, K. Suicide. Lancet 2009;373(9672):1372-81.

[3] Health, U. K. D. O. National suicide prevention strategy for England. London, United Kingdom: United Kingdom Department of Health 2002.

[4] National Crime Records Bureau, A. D. A. S. I. I. Ministry of Home Affairs Govt. of India 2008. 
[5] Vastag B. Suicide prevention plan calls for physicians help. JAMA 2001;285(21):2701-3.

[6] Schreiber J, Culpepper L, Fife A. Suicidal ideation and behavior in adults. UpTo Date 2010.

[7] Haukka J, Suominen, K, Partonen T, et al. Determinants and outcomes of serious attempted suicide: a nationwide study in Finland, 1996-2003. Am J Epidemiol 2008;167(10):1155-63.

[8] Tidemalm D, Langstrom N, Lichtenstein P, et al. Risk of suicide after suicide attempt according to coexisting psychiatric disorder: Swedish cohort study with long term follow-up. BMJ 2008;337:a2205.

[9] Dieserud G, Roysamb E, Ekeberg 0, et al. Toward an integrative model of suicide attempt: a cognitive psychological approach. Suicide Life Threat Behav 2001;31(2):153-68.

[10] Das PP, Grover S, Avasthi A, et al. Intentional self-harm seen in psychiatric referrals in a tertiary care hospital. Indian J Psychiatry 2008;50(3):187-91.

[11] Gururaj G. Epidemiology of suicide in Bangalore. Bangalore: National Institute of Mental Health \& Neuro Sciences 2001: p. 43.

[12] Hur JW, Lee BH, Lee SW, et al. Gender differences in suicidal behavior in Korea. Psychiatry Investig 2008;5(1):28-35.

[13] Suresh Kumar PN. An analysis of suicide attempters versus completers in Kerala. Indian J Psychiatry 2004;46(2):144-9.

[14] Dube SR, Anda RF, Felitti VJ, et al. Childhood abuse, household dysfunction, and the risk of attempted suicide throughout the life span: findings from the Adverse Childhood Experiences Study. JAMA 2001;286(24):3089-96.

[15] Qin P, Agerbo E, Mortensen PB. Suicide risk in relation to family history of completed suicide and psychiatric disorders: a nested case-control study based on longitudinal registers. Lancet 2002;360(9340):112630 .
[16] Chandrasekaran R, Gnanaseelan J, Sahai A, et al. Psychiatric and personality disorders in survivors following their first suicide attempt. Indian J Psychiatry 2003;45(2):45-8.

[17] Ponnudurai R, Jeyakar J, Saraswathy M. Attempted suicides in Madras. Indian J Psychiatry 1986;28(1):5962.

[18] Narang RL, Mishra BP, Nitesh M. Attempted suicide in Ludhiana. Indian J Psychiatry 2000;42(1):83-7.

[19] Ozdel O, Varma G, Atesci FC, et al. Characteristics of suicidal behavior in a Turkish sample. Crisis 2009;30(2):90-3.

[20] Nagendra Gouda M, Rao SM. Factors related to attempted suicide in Davanagere. Indian J Community Med 2008;33(1):15-8.

[21] Aghanwa H. The determinants of attempted suicide in a general hospital setting in Fiji Islands: a genderspecific study. Gen Hosp Psychiatry 2004;26(1):63-9.

[22] Logaraj M, Ethirajan N, Felix JW, et al. Suicidal attempts reported at a medical college hospital in Tamilnadu. Indian J Community Med 2005;30(4):1367.

[23] Welcher B, Rubin P, Nordentoft M. Admission of selfpoisoned patient during one year at the poisoning treatment centre, Copenhagen, Denmark. Acta Psychiatr Scand Suppl 1993;371:38-44.

[24] Blackmore ER, Munce S, Weller I, et al. Psychosocial and clinical correlates of suicidal acts: results from a national population survey. $\mathrm{Br} \mathrm{J}$ Psychiatry 2008;192(4):279-84.

[25] Kumar PN. Age and gender related analysis of psychosocial factors in attempted suicide. Indian J Psychiatry,1998;40(4):338-45.

[26] Raj MAJ, Kumaraiah V, Bhide AV. Social and clinical factors related to deliberate self-harm. Nimhans Journal 2000;18(1-2):3-18.

[27] Haw C, Hawton K, Houston K, et al. Psychiatric and personality disorders in deliberate self-harm patients. Br J Psychiatry 2001;178(1):48-54. 